\title{
Horizon meeting on cardiovascular physiology: Dedicated to Dr. Mike Sharratt ${ }^{1}$
}

\author{
Catherine F. Notarius, Robert C. Boushel, Maureen J. MacDonald, and J. Kevin Shoemaker
}

\begin{abstract}
This perspective document summarizes discussions held at the Canadian Society for Exercise Physiology Annual Meeting in Winnipeg on October 27, 2017, when an expert panel was assembled to discuss the key questions and challenges for future research in cardiovascular exercise physiology. We were inspired by the example of the late Dr. Mike Sharratt, an accomplished and impactful Professor in the Faculty of Kinesiology at the University of Waterloo. Dr. Sharratt had a unique ability to bring experts together and translate theory into action, with a central goal of optimizing the health benefits of exercise, particularly in the fields of cardiac rehabilitation and aging (University of Waterloo Applied Health Science Department 2016; University of Waterloo Health Science Newsletter, 10-1-2017 (http://uwaterloo.ca/applied-health-sciences/news/rememberingmike-sharratt)).
\end{abstract}

Key words: cardiovascular physiology, aging, cardiac rehabilitation, perspective.

Résumé : Ce document de perspective issu du Congrès annuel de la Société canadienne de physiologie de l'exercice le 27 octobre 2017 à Winnipeg présente un résumé des discussions d'un groupe de spécialistes au sujet des questions clés et des défis des recherches ultérieures en physiologie cardiovasculaire de l'exercice. Les discussions étaient inspirées du regretté Dr Mike Sharratt, professeur engagé et influent de la Faculté de kinésiologie de l'Université de Waterloo. Le Dr Sharratt savait de façon particulière rassembler des spécialistes afin de transposer la théorie dans l'action pour optimiser les bienfaits sanitaires de l'exercice physique, notamment dans le domaine de la réadaptation cardiaque et du vieillissement (Département des sciences appliquées à la santé, Université de Waterloo 2016; University of Waterloo Health Science Newsletter, 10-1-2017 (http://uwaterloo.ca/ applied-health-sciences/news/remembering-mike-sharratt)). [Traduit par la Rédaction]

Mots-clés : physiologie cardiovasculaire, vieillissement, réadaptation cardiaque, perspective.

\section{Introduction}

The role of the cardiovascular system is unique in human health and disease as it interacts with virtually every tissue and cell in the body and thus impacts almost all aspects of human physiological function. Because of this essential role for the cardiovascular system in integrative human physiology, it is no surprise that diseases of the cardiovascular system comprise the leading cause of death in the developed world, a statistic which is expected to increase as the population ages (GBD 2015 Mortality and Causes of Death Collaborators 2016).

Our objective in writing this perspective is to align, catalyze, and mobilize the Canadian exercise physiology field in addressing key questions in the area of cardiovascular control in health and disease. We envision that a positive outcome of this activity could be coordinated efforts on a future Pan-Canadian initiative. To begin this process, we will first summarize major achievements in the field of cardiovascular exercise physiology over the past 10 years; second, identify 3 key questions for further research in the next 10 years, with potential applications to the fields of aging and cardiac rehabilitation; third, reflect on what challenges may impact this research; and finally, what future contributor qualities and skills are needed to address these challenges.

\section{Past achievements in cardiovascular exercise physiology}

In the past 10 years, the cardiovascular risk of physical inactivity and sedentary behaviour has received increased attention, particularly with respect to the potential impact on both healthy aging and treatment of patients who suffer from various chronic cardiovascular diseases, such as coronary artery disease, heart failure, and hypertension (Ross et al. 2016). Lack of physical activity has been suggested to be a direct cause of a wide variety of chronic diseases (Booth et al. 2012). Equally recognized is the central role of exercise in the treatment of a vast number of chronic diseases (Pedersen and Saltin 2015). Some of the recent data on the cardiovascular effects of lifelong exercise training show remarkable preservation of cardiac and vascular function (Mortensen et al. 2012; Nyberg et al. 2013; Steding-Ehrenborg et al. 2015; Maessen

Received 21 February 2018. Accepted 18 June 2018.

C.F. Notarius.* University Health Network and Mount Sinai Hospital Division of Cardiology, University of Toronto, Toronto, ON M5G 2C4, Canada.

R.C. Boushel. ${ }^{\dagger}$ School of Kinesiology, University of British Columbia, Vancouver, BC V6T 1Z1, Canada.

M.J. MacDonald. ${ }^{\dagger}$ Department of Kinesiology, McMaster University, Hamilton, ON L8S 4K1, Canada.

J.K. Shoemaker. ${ }^{+}$School of Kinesiology, The University of Western Ontario, London, ON N6A 3K7, Canada.

Corresponding author: Catherine F. Notarius (email: c.notarius@utoronto.ca).

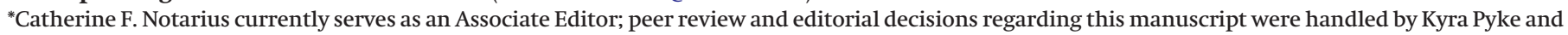
Terry Graham.

†Note the authors following the first author are listed in alphabetical order.

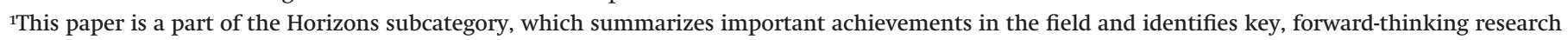
questions and challenges that need to be addressed.

Copyright remains with the author(s) or their institution(s). Permission for reuse (free in most cases) can be obtained from RightsLink. 
et al. 2017). Advances have been made in further identifying specific and redundant pathways for muscle vasodilation during exercise (Joyner and Casey 2014). Other recent findings point to potential exercise sensing mechanisms in the endothelium, which may explain the coordinated cardiovascular adaptations to training (Beech 2018). The effect of acute and chronic exercise on both cardiac and arterial function in health and disease remains an active area of research that holds much promise.

Significant advances in knowledge have also occurred in the area of exercise and brain function as well as microcirculatory studies of oxygen delivery. Progress in these areas of research have been aided by technological advances in imaging techniques as well as data processing and other technologies related to assessment of vascular structure and function (Thijssen et al. 2011; Coverdale et al. 2014; Amelard et al. 2017) over the past 10 years. The work on brain blood flow and imaging of flow/brain activation patterns during exercise have led to significant advances in our understanding of the complex relationships between blood flow and brain function (MacIntosh et al. 2014). Aging and disease seem to be synergistic in their negative effect on brain function. Cardiac patients appear to have accelerated brain atrophy for their age as well as an augmented age-related impairment of cerebrovascular control that emphasize reduced dilatory responses in large conduit arteries as well as vascular structure downstream (Anazodo et al. 2015). However, cardiac rehabilitation appears to "regrow" cortical thickness in disparate parts of the brain and improve regional blood flow patterns (Anazodo et al. 2015). Imaging at the microcirculatory level in skeletal muscle has revealed a distinction between plasma versus erythrocyte flow in capillary networks (Fraser et al. 2013) and the role of the red cell in both $\mathrm{O}_{2}$ sensing and vasodilator release has raised important questions about flow regulation (Ellis et al. 2010; Murrant et al. 2017). There has also been important work on the interaction between organ systems, including sex differences (Hart et al. 2009, 2011; Howden et al. 2015; Dominelli et al. 2017). These topics highlight the value of integrative physiology research rather than reductionism alone, as expressed by Joyner (Joyner and Pedersen 2011), particularly when applied to the ultimate goal of improving human cardiovascular health and reducing cardiovascular disease risk.

The idea of regular exercise as a means of attenuating or abolishing the decline in cardiovascular fitness and function that occurs with aging is now well accepted (Garatachea et al. 2015). At a recent American Physiological Society conference on Cardiovascular Aging, Doug Seals identified adverse changes in arteries, in particular large artery stiffening and endothelial dysfunction, as responsible for much of the increase in cardiovascular disease risk with age. He and his colleagues have shown that both chronic oxidative stress and inflammation are important factors leading to arterial dysfunction with age (Seals et al. 2018). Dr. Seals highlighted regular aerobic exercise and a healthy diet as well established strategies to counteract these negative effects on the vasculature (Seals et al. 2018) and others have demonstrated how varying exercise mode, intensity, and duration can impact endothelial function in different ways (Thijssen et al. 2009; Shenouda et al. 2017). In addition, physiological studies made on astronauts during spaceflight (model of extreme inactivity) have found increases in carotid artery stiffening equivalent to several decades of aging (Hughson et al. 2016). Bed rest studies suggest that exercise can counter some of the accelerated aging effects of zero gravity in space (Krainski et al. 2014; Hughson et al. 2016) and may inform related work on earth.

Guidelines for physical activity for the general adult and older adult healthy population (Paterson and Warburton 2010) as well as children (Tremblay et al. 2011) and those with specific disabilities (Latimer-Cheung et al. 2013) including cardiovascular diseases have been released in Canada. This completed the initial background development work originally spearheaded by Mike Sharratt (Sharratt and Hearst 2007). This concept of best-evidence integra- tion of exercise prescription and the assertion that exercise should be at the forefront of a health management plan, is an idea that is central to the Exercise is Medicine initiative launched by the American College of Sports Medicine 10 years ago in 2007 in the United States, which is now in 43 other countries. This initiative became Exercise is Medicine Canada when launched by the Canadian Society for Exercise Physiology in Canada in 2011 with a goal to educate stakeholders to include a discussion of exercise in primary medicine interactions (Fowles et al. 2018).

Despite many of these technology-driven research advances and public health initiatives, there remains much research to be done going forward to address key questions that remain in cardiovascular exercise physiology, including identifying the mechanisms by which exercise influences all aspects of cardiovascular benefit and what specific type, intensity, duration, and frequency of exercise training is optimal for an individual in both health and disease.

\section{Key directions for future research}

Any discussion of future work in any area of physiology starts with an idea or question and while this usually is within the domain of the research scientist, it is influenced heavily by funding agencies and their agenda. In this era of rapidly developing technologies, it is important to emphasize that the research question should not be driven only by a specific new technology, but perhaps facilitated by technological developments where possible. Framing a question in broader terms, such as why it is important to know, appears self-evident but is a crucial step required to avoid work that does not contribute to the greater knowledge base that will inform improvements in human health. In this regard, computational biology and bioinformatics are likely to impact research questions and design. Collaboration between individual scientists as well as institutions would allow broad-based plans to address the regulation of the cardiovascular system in different disorders and determine what is effective and feasible to maintain cardiovascular health throughout life for both athletes and nonathletes. Also, the optimization of exercise prescription delivery needs to be studied so that a common target can be articulated and feasible delivery developed in both healthy and disease populations. This development of a common target may require an operational basis for scientists to identify key questions and assemble a team. We have seen effective examples of this in the past, specifically with John Sutton and Operation Everest II (Sutton et al. 1983; Wagner 2010) as well as the spaceflight work by Hughson and colleagues where the questions are coordinated and an operational approach is used to maximize impact (Hughson et al. 2017). This was also the approach used by foundational leaders in our field such as Bengt Saltin (Joyner 2017). Coordinating questions across institutions and between research programs with differing, yet complimentary expertise, may help address why there is so much individual variation in data, for example in response to exercise training. Reflex control of the cardiovascular system could vary between individuals and affect training responses as well as individual cardiovascular risk, but this concept has not been systematically addressed.

We still do not have a refined understanding of the matching between-flow and tissue metabolism at the micro-tissue level. We have learned much about responses to different training approaches, but the next era will likely address individualized dose of training for lifelong health. The emerging area of inter-organ signalling/communication will contribute to an integrative understanding of cardiovascular health at the discrete level from minimal (e.g., reduced sitting time) to optimal amount of exercise for health. Cardiovascular physiology can then be linked to cardiovascular health throughout life from high-performance athletes to cardiovascular disease patients and the mechanisms of benefit clearly identified. In terms of theoretical advances, we 
need to employ some emerging data analytical techniques to address the question of the best assessments to "predict" the response of an individual to an exercise training program and tailor those programs to the individual cardiovascular status at baseline. We also need to ensure that we are facilitating the translation of individual physiological investigations into larger scale multi-site, coordinated trials that consider exercise program feasibility and adherence to examine safety and impact in large scale interventions.

The information we know about cardiovascular physiology in terms of the heart and blood vessels should be linked in the future to other specialized fields of study such as the brain to recognize the impact on other systems and link it back to cardiovascular function. For example, since exercise increases cerebral blood flow (Smith and Ainslie 2017), improved cardiovascular function likely increases brain function. Brain structure has been shown to increase as a result of long-term endurance training (Wood et al. 2016). This change in brain structure may contribute to countering the effects of aging with regular exercise but we need to understand the underlying mechanisms as well as those mediating impaired stroke outcomes and autonomic impairments common in cardiovascular diseases such as coronary artery disease, heart failure, and hypertension. The extent to which exercise can restore autonomic and cerebrovascular outcomes in these patients is currently unknown.

Thus the 3 major directions for future research in cardiovascular physiology our panel has identified include (i) development of an operational approach to coordinating key questions to explain variable responses to acute and chronic exercise interventions and how to individualize training to tailor the benefit; (ii) develop projects that link cardiovascular physiology to cardiovascular health throughout life from high-performance athletes to cardiovascular disease with the focus on mechanisms of benefit; and (iii) link cardiovascular physiological studies with other specialized areas that can be impacted by cardiovascular benefits of exercise or adversely affected by aging or cardiovascular disease, such as neurological outcomes related to structure, vascular and functional aspects of brain health, and neural control of the cardiovascular system.

\section{Challenges}

An important challenge to future work in this field is the limit of technology in studying the microcirculation and as well as arterial stress during exercise in humans. We lack technologies that can accurately measure the microcirculation and regional organ responses in humans during exercise. Advancements in biomedical engineering enabling improved imaging of metabolism and the circulation in both the laboratory and the field would markedly enhance the ability to study and uncover mechanisms of cardiovascular regulation. Key challenges that need to be addressed include some technical advances for the following measurements in integrated human exercise physiology models: the ability to measure the "stress" of exercise in arteries (not just before and after), and being able to move our measurements beyond the typically accessible conduit arteries. There is also poor temporal resolution of magnetic resonance imaging (MRI)-based methods and poor options for non-MRI systems to track cerebrovascular outcomes in humans (Lindenholz et al. 2018).

Another challenge to human cardiovascular physiology research is recruitment of subjects, both healthy and those with disease. For the former, there should be an equal recruitment of both men and women; indeed, describing sex-differences in responses forms a fundamental goal for our community (and others). Recruitment of patients with various cardiovascular disorders can be challenging if a good relationship is not developed with a clinical partner. In this role, physicians are often unavailable if needed for studies and direct involvement is not usually part of their job structure or reimbursement. We need creative solutions to these challenges. Some examples include collaboration on grant applications for projects of shared interest that will benefit both scientist and physician but the relationship requires time to develop. Recruiting cardiac patients for training studies can be aided by recruiting a family member or friend as well. This may help to reduce future adherence issues during the training period.

There is also a need to improve and coordinate graduate student education in integrative physiology. Each university curriculum currently is unique with respect to required graduate courses but there is the potential to share graduate course platforms using e-learning technology to maximize the student experience and ensure a basic grounding in integrative physiology and methods.

Thus, the 3 main challenges to human cardiovascular research which we have identified include (i) improved technology to enhance study methods including the microvasculature, arterial function, and the brain; (ii) encourage sex-balanced recruitment of subjects and develop medical partnerships to gain access to recruit patient groups; and (iii) promote a coordinated approach to graduate student education in integrative physiology.

\section{Students: qualities and skills needed to address these challenges}

This is an area where we can look to Dr. Sharratt's impact as a teacher and mentor. What his former graduate students (authors M.J.M. and J.K.S. among them) remember most was his passion, integrity, and enthusiasm that he brought to every encounter. We need to ensure that young scientists are being encouraged to be excellent colleagues who have a life-long passion to answer interesting questions about human performance and health. This team-based approach is also able to accommodate all types of students and educational backgrounds. Of course, students need a baseline of technical and academic skills and a willingness to work hard, but other aspects of a career should not be forgotten. Throughout his career at the University of Waterloo, Dr. Sharratt was also a great example of how to develop and mentor students, from fostering a love of science to making sure they have passions aside from work with an emphasis on staying active and healthy. Those things will carry the students of today through the many ups and downs that are sure to appear in their future career.

Some of the specific attributes for student success have not changed over the years; passion, curiosity, enthusiasm, dedication, perseverance, analytical skills, intellect, writing ability, communication skills, and importantly to collaborate, support colleagues, and contribute to a positive working environment. In the rapidly changing world of science, young scientists can play a major role in advancing the field by bringing unique, diverse discipline skills, such as computer and data science, biomedical engineering, bioinformatics, communications, program management, and leadership skills, to list a few examples. Beyond the traditional academic scientist, there will be diverse roles for the scientist in the future. Young scientists can envision shaping their own unique professional niche.

What is the fundamental knowledge necessary for graduate students today? In the current scientific environment, the emphasis is on reductionism (Joyner and Pedersen 2011). While this type of science is necessary and important, it is also crucial not to ignore the benefit of a sound knowledge of integrative physiology, which encourages forming fundamental research questions and allows translation of theory into action. This will optimize human health benefits particularly with respect to exercise, and is especially relevant in the growing fields of cardiac rehabilitation and aging, 2 clinical areas in which Dr. Sharratt was most active and form an important part of his enduring legacy.

In the present funding climate in Canada, it makes sense to form collaborations to be able to train the next generation of 
graduate students, perhaps in a country-wide manner, and be able to answer the next large important questions in cardiovascular physiology that will have the most impact on the health of Canadians in the future.

\section{Conflict of interest statement}

The authors have no conflicts of interest to report.

\section{References}

Amelard, R., Hughson, R.L., Greaves, D.K., Pfisterer, K.J., Leung, J., Clausi, D.A., and Wong, A. 2017. Non-contact hemodynamic imaging reveals the jugular venous pulse waveform. Sci. Rep. 7: 40150. doi:10.1038/srep40150. PMID: 28065933.

Anazodo, U.C., Shoemaker, J.K., Suskin, N., Ssali, T., Wang, D.J., and St. Lawrence, K.S. 2015. Impaired cerebrovascular function in coronary artery disease patients and recovery following cardiac rehabilitation. Front. Aging Neurosci. 7: 224. doi:10.3389/fnagi.2015.00224. PMID:26779011.

Beech, D.J. 2018. Endothelial piezo 1 channels as sensors of exercise. J. Physiol. 596: 979-984. doi:10.1113/JP274396. PMID:29194632.

Booth, F.W., Roberts, C.K., and Laye, M.J. 2012. Lack of exercise is a major cause of chronic diseases. Compr. Physiol. 2: 1143-1211. doi:10.1002/cphy.c110025. PMID:23798298.

Coverdale, N.S., Gati, J.S., Opalevych, O., Perrotta, A., and Shoemaker, J.K. 2014. Cerebral blood flow velocity underestimates cerebral blood flow during modest hypercapnia and hypocapnia. J. Appl. Physiol. 117: 1090-1096. doi:10.1152/ japplphysiol.00285.2014. PMID:25012027.

Dominelli, P.B., Molgat-Seon, Y., Griesdale, D.E.G., Peters, C.M., Blouin, J.S., Sekhon, M., et al. 2017. Exercise-induced quadriceps muscle fatigue in men and women: effects of arterial oxygen content and respiratory muscle work. J. Physiol. 595(15): 5227-5244. doi:10.1113/JP274068. PMID:28524229.

Ellis, C.G., Goldman, D., Hanson, M., Stephenson, A.H., Milkovich, S., Benlamrli, A., et al. 2010. Defects in oxygen supply to skeletal muscle of prediabetic ZDF rats. Am. J. Physiol. Heart Circ. Physiol. 298: H1661-H1670. doi:10.1152/ajpheart.01239.2009. PMID:20207810.

Fowles, J.R., O'Brien, M.W., Solmundson, K., Oh, P.I., and Shields, C.A. 2018. Exercise is Medicine Canada physical activity counselling and exercise prescription training improves counselling, prescription and referral practices among physicians across Canada. Appl. Physiol. Nutr. Metab. 43(5): 535-539. doi:10.1139/apnm-2017-0763. PMID:29316409.

Fraser, G.M., Goldman, D., and Ellis, C.G. 2013. Comparison of generated parallel capillary arrays to three-dimensional reconstructed capillary networks in modeling oxygen transport in discrete microvascular volumes. Microcirculation, 20(8): 748-763. PMID:23841679.

Garatachea, N., Pareja-Galeano, H., Sanchis-Gomar, F., Santos-Lozano, A., Fiuza-Luces, C., Moran, M., et al. 2015. Exercise attenuates the major hallmarks of aging. Rejuvenation Res. 18: 57-89. doi:10.1089/rej.2014.1623. PMID: 25431878.

GBD 2015 Mortality and Causes of Death Collaborators. 2016. Global, regional, and national life expectancy, all-cause mortality and cause-specific mortality for 249 causes of death, 1980-2015: a systematic analysis for the Global Burden of Disease Study 2015. Lancet, 388: 1459-1544. doi:10.1016/S0140-6736 (16)31012-1. PMID:27733281.

Hart, E.C., Charkoudian, N., Wallin, B.G., Curry, T.B., Eisenach, J.H., and Joyner, M.J. 2009. Sex differences in sympathetic neural-hemodynamic balance. Hypertension, 53: 571-576. doi:10.1161/HYPERTENSIONAHA.108.126391. PMID:19171792.

Hart, E.C., Charkoudian, N., Wallin, B.G., Curry, T.B., Eisenach, J., and Joyner, M.J. 2011. Sex and ageing differences in resting arterial pressure regulation: the role of the $\beta$-adrenergic receptors. J. Physiol. 589: 5285-5297. doi:10.1113/jphysiol.2011.212753. PMID:21859824.

Howden, E.J., Perhonen, M., Peshock, R.M., Zhang, R., Arbab-Zadeh, A., Adams-Huet, B., and Levine, B.D. 2015. Females have a blunted cardiovascular response to one year of intensive supervised endurance training. J. Appl. Physiol. 119: 37-46. doi:10.1152/japplphysiol.00092.2015. PMID:25930024.

Hughson, R.L., Robertson, A.D., Arbeille, P., Shoemaker, J.K., Rush, J.W., Fraser, K.S., et al. 2016. Increased postflight carotid artery stiffness and inflight insulin resistance resulting from 6-mo spaceflight in male and female astronauts. Am. J. Physiol. Heart Circ. Physiol. 310: H628-H638. doi:10.1152/ ajpheart.00802.2015.

Hughson, R.L., Helm, A., and Durante, M. 2017. Heart in space: effect of the extraterrestrial environment on the cardiovascular system. Nat. Rev. Cardiol. 15: 167-180. doi:10.1038/nrcardio.2017.157. PMID:29053152.

Joyner, M.J. 2017. Bengt Saltin and exercise physiology: a perspective. Appl. Physiol. Nutr. Metab. 42(1): 101-103. doi:10.1139/apnm-2016-0314. PMID:27959640.

Joyner, M.J., and Casey, D.P. 2014. Muscle blood flow, hypoxia, and hypoperfusion. J. Appl. Physiol. 116: 852-857. doi:10.1152/japplphysiol.00620.2013. PMID:23887898.

Joyner, M.J., and Pedersen, B.K. 2011. Ten questions about systems biology. J. Physiol. 589(5): 1017-1030. doi:10.1113/jphysiol.2010.201509. PMID:21224238.

Krainski, F., Hastings, J.L., Heinicke, K., Romain, N., Pacini, E.L., Snell, P.G., et al.
2014. The effect of rowing ergometry and resistive exercise on skeletal muscle structure and function during bed rest. J. Appl. Physiol. 116: 1569-1581. doi:10.1152/japplphysiol.00803.2013. PMID:24790012.

Latimer-Cheung, A.E., Martin Ginis, K.A., Hicks, A.L., Moti, R.W., Pilutti, L.A., Duggen, M., et al. 2013. Development of evidence-informed physical activity guidelines for adults with multiple sclerosis. Arch. Phys. Med. Rehabil. 94: 1829-1836. doi:10.1016/j.apmr.2013.05.015. PMID:23770262.

Lindenholz, A., van der Kolk, A.G., Zwanenburg, J.J.M., and Hendrikse, J. 2018. The use and pitfalls of intracranial vessel wall imaging: how we do it. Radiology, 286: 12-28. doi:10.1148/radiol.2017162096. PMID:29261469.

MacIntosh, B.J., Swardfager, W., Crane, D.E., Ranepura, N., Saleem, M., Oh, P.I., et al. 2014. Cardiopulmonary fitness correlates with regional cerebral grey matter perfusion and density in men with coronary artery disease. PLoS ONE, 9: e91251. doi:10.1371/journal.pone.0091251. PMID:24622163.

Maessen, M.F.H., van Mil, A.C.C.M., Straathof, Y., Riksen, N.P., Rongen, G.A.P., Hopman, M.T.E., et al. 2017. Impact of lifelong exercise training on endothelial ischemia-reperfusion and ischemic preconditioning in humans. Am. J. Physiol. Regul. Integr. Comp. Physiol. 312: R828-R834. doi:10.1152/ajpregu. 00466.2016.

Mortensen, SP, Nyberg, M., Winding, K., and Saltin, B. 2012. Lifelong physical activity preserves functional sympatholysis and purinergic signalling in the ageing human leg. J. Physiol. 590(23): 6227-6236. doi:10.1113/jphysiol.2012. 240093. PMID:22966164.

Murrant, C.L., Lamb, I.R., and Novielli, N.M. 2017. Capillary endothelial cells as coordinators of skeletal muscle blood flow during active hyperemia. Microcirculation, 24: e12348. doi:10.1111/micc.12348.

Nyberg, M., Mortensen, S.P., and Hellsten, Y. 2013. Physical activity opposes the age-related increase in skeletal muscle and plasma endothelin-1 levels and normalizes plasma endothelin-1 levels in individuals with essential hypertension. Acta Physiol. (Oxf.), 207(3): 524-535. doi:10.1111/apha.12048.

Paterson, D.H., and Warburton, D.E. 2010. Physical activity and functional limitations in older adults: a systematic review related to Canada's Physical Activity Guidelines. Int. J. Behav. Nutr. Phys. Act. 7: 38. doi:10.1186/1479-58687-38. PMID:20459782.

Pedersen, B.K., and Saltin, B. 2015. Exercise as medicine - evidence for prescribing exercise as therapy in 26 different chronic diseases. Scand. J. Med. Sci. Sports, 25(S3): 1-72. PMID:26606383.

Ross, R., Blair, S.N., Arena, R., Church, T.S., Despres, J.P., Franklin, B.A., et al on behalf of the American Heart Association Physical Activity Committee of the Council on Lifestyle and Cardiometabolic Health. 2016. AHA Scientific Statement: Importance of assessing cardiorespiratory fitness in clinical practice. A case for fitness as a clinical vital sign. Circulation, 134: e653-e699. PMID: 27881567.

Seals, D.R., Brunt, V.E., and Rossman, M.J. 2018. Strategies for optimal cardiovascular aging. Am. J. Physiol. Heart Circ. Physiol. 60: 418. doi:10.1152/ajpheart. 00734.2017. PMID:29652545.

Sharratt, M.T., and Hearst, W.E. 2007. Canada's physical activity guides: background, process, and development. Can. J. Publ. Health, 98: S9-S15. PMID: 18213939.

Shenouda, N., Gillen, J.B., Gibala, M.J., and MacDonald, M.J. 2017. Changes in brachial artery endothelial function and resting diameter with moderateintensity continuous but not sprint interval training in sedentary men. J. Appl. Physiol. 123: 773-780. doi:10.1152/japplphysiol.00058.2017. PMID: 28546466.

Smith, K.J., and Ainslie, P.N. 2017. Regulation of cerebral blood flow and metabolism during exercise. Exp. Physiol. 102: 1356-1371. doi:10.1113/EP086249. PMID:28786150.

Steding-Ehrenborg, K., Boushel, R.C., Calbet, J.A., Åkeson, P., and Mortensen, S.P. 2015. Left ventricular atrioventricular plane displacement is preserved with lifelong endurance training and is the main determinant of maximal cardiac output. J. Physiol. 593(23): 5157-5166. doi:10.1113/JP271621. PMID:26496146.

Sutton, J.R., Maher, J.T., and Houston, C.S. 1983. Operation Everest II. Prog. Clin. Biol. Res. 136: 221-233. PMID:6665023.

Thijssen, D.H., Dawson, E.A., Black, M.A., Hopman, M.T., Cable, N.T., and Green, D.J. 2009. Brachial artery blood flow responses to different modalities of lower limb exercise. Med. Sci. Sports Exerc. 41: 1072-1079. doi:10.1249/MSS. 0b013e3181923957. PMID:19346980.

Thijssen, D.H., Black, M.A., Pyke, K.E., Padilla, J., Atkinson, G., Harris, R.A., et al. 2011. Assessment of flow-mediated dilation in humans: a methodological and physiological guideline. Am. J. Physiol. Heart Circ. Physiol. 300: H2-H12. doi:10.1152/ajpheart.00471.2010.

Tremblay, M.S., Warburton, D.E., Janssen, I., Paterson, D.H., Latimer, A.E., Rhodes, R.E., et al. 2011. New Canadian physical activity guidelines. Appl. Physiol. Nutr. Metab. 36(1): 36-46. doi:10.1139/H11-009. PMID:21326376.

Wagner, P.D. 2010. Operation Everest II. High Alt. Med. Biol. 11: 111-119. doi:10. 1089/ham.2009.1084. PMID:20586595.

Wood, K.N., Nikolov, R., and Shoemaker, J.K. 2016. Impact of long-term endurance training vs. guideline-based physical activity on brain structure in healthy aging. Front. Aging Neurosci. 8: 155. [eCollection.] doi:10.3389/fnagi. 2016.00155. PMID:27445798. 